\title{
A Psychological Reading of J. D. Salinger's “For Esme with Love and Squalor"
}

\author{
Morteza Habibi Nesami ${ }^{1}$, Asghar Moulavi Nafchi ${ }^{2 *}$ \\ ${ }^{1} \mathrm{PhD}$ in English Literature, Freelance Tutor and Researcher \\ ${ }^{2}$ Senior Lecturer, Hakim Sabzevari University, Iran \\ Corresponding Author: a.moulavi.n@gmail.com
}

\begin{abstract}
Keywords: Defense mechanism, For Esme with Love and Squalor, J. D. Salinger, Psychoanalysis, Psychology, Psychoneurotic.
\end{abstract}

\begin{abstract}
The $20^{\text {th }}$ century has witnessed a plethora of war stories, but among them Salinger's "For Esme with Love and Squalor," a minor masterpiece as Paul Alexander calls it, stands out. It also falls among those typical Salingerian child-adult relationships that highlight the non-phony members of society with many things in common distinguishing them from the other so-called normal members of the society. In the current study, characters are studied from a psychological point of view and classified into two major groups by the researchers. The first group and the main focus of the study is the minority of society and the second group relates to the majority or commonality. The minority group includes Salinger's heroes and protagonists who are later known as psychoneurotic. This first group feels affinity to the children who are far away from the hostility and harshness of adults' world as, to Salinger, the concept of innocence means being away from the false standards and hypocrisy of the majority of the insensitive society. The researchers try to distinguish between these two groups from different psychological and psychoanalytic aspects. Despite the contrast between these two groups, there are some similarities in their sexual conceptions and psychological adjustment that clarify similarities in traits and responses in the form of adopting different mechanisms to adjust and remove tensions and alleviate anxiety employing the mechanisms Freud calls palliative remedies.
\end{abstract}

\section{INTRODUCTION}

As a whole Salinger's characters suffer from the chaotic situation following a World War with its pervasive social impacts. But the question is why Salinger chose his heroes mostly from among children and outcast adults. The seed for this study has been sown by a set of simple questions: Why are Salinger's heroes different from the rest of the society or commonalities? Why do the readers of Salinger's stories feel sympathy toward the heroes or protagonists? Are Salinger's heroes called normal or abnormal? What is the definition of normality and abnormality? Is it right to call his heroes psychoneurotic? What factors make an individual neurotic? Are neurotic people insane? Does Salinger find any affinities between himself and his heroes? As a matter of fact the significance of this study is in responding to such questions.

\subsection{The Writer's Background}

A brief look at Salinger's biography would reveal that he himself is a kind of psychoneurotic that adopted isolation and alienation. Looking deeper into his stories, the reader can definitely feel the presence of the writer of the work as a character drawing on his background. Salinger's characters, namely, children, military personnel, psychoneurotic adults, along with the setting and family relationships, somehow represent his own life and his very state of mind.

\subsection{Literature Review}

Gwynn \& Blonter (1962) argue that a half-dozen of Salinger's short pieces of fiction are nearly perfectly organized works, with a variety of organizations in which vivid human characters are involved in the basic human conflict between love and what Salinger's Esme calls squalor, in which the characters and conflict are embodied in original and memorable symbols that are often 
humorous, even as the dialogue and narration are always humorous. Gwynne \& Blotner's study of Salinger's works has little concern with the author himself for two reasons. Firstly they are chiefly interested in discovering specific elements in each work that contribute to the success or failure of the work. Secondly, it would be very difficult for them to see the author in his fiction, because they claim almost everything about this popular writer is unknown to the public.

Grunwald (1962) is considered an important work of criticism featuring more than twenty of the most important American critics including Arthur Mizener, Alfred Kazin, Granville Hicks, Maxwell Geismar, and John Updike. In this collection, Salinger and his works are examined objectively. Grunwald the editor and the writer of the introduction to this collection, contends that Salinger's critics runs along a fairly clear ideological and philosophical spectrum, from left to right. On the left are the critics who regard Salinger as a sociological writer whose theme is man vs. society, the individual vs. conformity. On the right, moving to the extreme, are the critics who see Salinger as a religious novelist in whom the theme of incarnation is remarkable.

Alexander (1996) believes that the pattern of Salinger's fiction, hence the approach which critics take toward it, is generally that of a misfit hero, a child or adult, caught up in a world that emerges as both phony and nice. Many of these protagonists themselves are a mixture of deplorable, mean qualities (phoniness), and appealing, often tender-comic innocence, that is, niceness. In any case, these characters are embattled against a world which often seems confusing, phony, and nice at the same time.

\subsection{Methodology and Approach}

The appropriate literary approach to study Salinger's characters, especially his distinguished heroes, is a psychological approach. It is in fact an excellent tool for reading beneath the lines and analyzing the character's behavior. Freud is one of the forerunners of psychological literary criticism. As stated in Thurschwell (2009), Freud the critic acts like Freud the analyst. He scrutinizes the texts carefully to expose motivations that make the characters in the book and the story, behave as they do. He often finds that these motivating factors trace back to a character's past, yet some objections are still raised against his method. The question is how one can interpret the motives of a character in a book as related to their childhood fantasies and desires when we know, in fact, that the character is simply an invention of the author and has never had a real childhood at all. Of course, by analyzing the characters in a work of fiction the critic can, to some extent, recognize the author's state of mind. Freud's criticism of specific works of art and literature typically examines the psychic motives of either the characters in the work or the artists themselves; therefore, by analyzing the characters in Salinger's stories, it would be possible to read the book of his mind. Careful examination of Salinger's biography reveals that his heroes have some characteristics of the writer himself.

A study of sexuality and love in accordance with Freudian psychology will be applied on the stories. First, sexual aberration will be detected in the characters. Adults who chose children as sexual object are introduced as aberrant according to Freudian theories of sexuality, but in Salinger's stories the case is slightly different. Moreover, in special cases, fetishism, touching, and looking is considered as aberration. Accordingly, some of the characters will be discovered as aberrant and some not. Next, the concept of sexuality has been investigated in children, too. The attitudes of children in the stories may be examined according to Freudian theory of infantile sexuality and infantile sexual object choice during infancy, as the after effect of infantile object choice has better be studied in adolescents and adults.

The theory of adjustment in psychology, too, is included here. According to Shaffer \& Shoben (1956), almost everyone uses certain devices to retain their psychological equilibrium. These devices are generally known as adjustment mechanisms. The excessive dependency on any of the mechanisms can lead to further difficulties. The adjustment mechanisms are classified into several groups. The most important are adjustment by defense, escape, and illness. The major mechanisms for adjustment like denial, rationalization, compensation, and displacement are known as defensive mechanisms. Escape mechanisms consists of isolation and fantasy. Each of these mechanisms will hopefully be traced in the stories, and isolation as an important theme in Salinger's 
stories may be emphasized more than the other mechanisms. There are different reasons for one to adopt isolation and to become alienated. Social pressure and parental alienation are the most important ones. In fact according to Freud (1968), there are three major sources of suffering for human beings which are suffering from one's own body, the outer world, and finally one's relations with other men. So the reasons for alienation and isolation in the characters within the stories is worth clarification.

Neurosis as a psychological disorder will be discussed and will be differentiated from neurosis as an illness. Both will be traced in the characters of the stories. Besides, normality and abnormality will be defined and clarified according to psychological theories. By defining these terms and applying them on the stories, Salinger's protagonists will be analyzed and what Salinger had in mind should then be partly illustrated. In fact, the researchers act like a psychologist or psychoanalyst to analyze characters and subsequently the writer himself, because according to Freud every work of art is like the dream of the creator which should be interpreted. The interpretation of this dream will represent the creator's unconscious (Thurschwell, 2009).

\section{DISCUSSION}

\subsection{Esme and Sergeant X's Drive for Sexuality}

On the surface, neither of Salinger's heroes may show the slightest inclination towards sexual desire, but the stark reality is that their unconscious sexual tendency toward an atypical sexual object is worth consideration. Therefore, in this study, through the lens of Freudian Psychoanalysis, sexuality would be detected in Salinger's non-phony characters both children and a minority of adults. The aim is to sift through evidence in the story and to investigate the roots of sexual tendency in the characters to see whether Salinger's characters are different in sexual relationships or not, as this scrutiny can be a marked comparison between the two character types.

\subsubsection{Sexual Aberration}

One of the angles, from which characters should be analyzed, is Sexual aberration. Freud (1974) begins his first essay on the sexual aberrations by distinguishing between the sexual object and the sexual aim - noting that deviations from the norm could occur with respect to both. The sexual object is therein defined as a desired object, and the sexual aim as what acts are desired with the anticipated object. Discussing the choice of children and animals as sex objects - pedophilia and bestiality - he notes that most people would prefer to limit these perversions to the insane on aesthetic grounds, but that they exist in normal people also. Freud also explores deviations of sexual aims, as in the tendency to linger over preparatory sexual aspects such as looking and touching (Quinodoz, 2004). Turning to neurotics, Freud (1974) emphasizes that in them tendencies to every kind of perversion can be shown to exist as unconscious forces ... neurosis is, as it were, the negative of perversion. Freud (1938) also makes the point that people who are behaviorally abnormal are always sexually abnormal in experience but that many people who are normal behaviorally otherwise are sexually abnormal also. Freud (1974) concludes that a disposition to perversions is an original and universal disposition of the human sexual instinct and that ... this postulated constitution, containing the germs of all the perversions, will only be demonstrable in children.

\subsubsection{Children Chosen as Sexual Object: Pedophilia}

According to Freud (1974), children at times become the target of adults as sexual objects, and since children are not typically involved in sexual relationship, it is considered as a kind of aberration. Therefore, adults who show the slightest tendency toward these abnormal relationships are called aberrant. Cases in which sexually immature persons, children, are chosen as sexual objects are instantly judged as sporadic aberration. It is only exceptionally that children are the exclusive sexual objects in such a case. They usually come to play part when someone who is cowardly or has become impotent adopts them as a substitute or when an urgent instinct, one which cannot allow of postponement, cannot at the moment get possession of any more appropriate object. 
The sexual abuse of children is found with uncanny frequency among schoolteachers and child attendants, simply because they have best opportunity for it.

In "For Esme with Love and Squalor", Sergeant X, a married man, whose specialized preinvasion course in the army has just ended, reads on a bulletin board an announcement of children's choir practice:

At three-fifteen, the board stated, there would be children's choir-practice ... A sheet of paper was tacked up, listing the names of the children expected to attend practice. I stood in the rain and read all the names, then entered the church (Salinger, 1961, p. 67).

Sargent X's tendency toward children as sexual objects is obvious in this part. What makes the reader ponder here is that he preferred to stand in the rain and get wet to read all the names of the children, and definitely found out that most of them were girls. When he entered the church he saw about twenty children, mostly girls from seven to thirteen. One of them about thirteen appealed to him even sexually. In the teahouse where they met, she gave him a smile and he smiled back. By vivid description that Sergeant $\mathrm{X}$ gives about the appearance of Esme, his sexual inclination toward the girl can be inferred. The reader, from the very beginning of the story, learns that he was far from his wife for at least three weeks for pre-invasion training course as letter writing of the soldiers verifies the fact. Hence, as soon as the course ended, he got acquainted with the girl and was sexually attracted to her. His urgent instinct made him find the girl appropriate to fulfill his sexual desires, because according to Freud he could not find any appropriate sexual object in the barrack and so Esme, the little girl could be an immediate replacement. According to Habibi (2011), this is also true of Saymour in Salinger's "A Perfect Day for a Bananafish," another story in the same collection. This is a story in which a dual sexual desire is formed between Seymour, who is like Sargent $\mathrm{X}$ a soldier of the war, and Sybil, the little girl playing alone on the beach.

\subsubsection{Touching and Looking: Voyeurism}

According to Freud (1974), touching can scarcely be counted as aberration, because a certain degree of it is normal before the normal sexual aim. Influx of excitation attained by the tactile sensation of the sexual object's skin is ordinary and normal in sexual forepleasure; therefore, there is certain amount of it in everyone. For example, in "Uncle Wiggly in Connecticut," Eloise describes how her boyfriend Walt touched her stomach and said it was beautiful, so this is exactly the tactile sensation of skin in the sexual object, Eloise, and cannot be considered as aberration. Equally, in "Pretty Mouth and Green My Eyes," the tactile connection between the man and woman in bed is not considered as aberration, because it is normal in sexual intercourse or forepleasure. By the same token, the same is true about looking. Visual impression is another way by which libidinal excitation is aroused, so a certain amount of looking is not aberration except in some special cases. In this regard Freud (1974) claims:

“... pleasure in looking [scopophilia] becomes a perversion (a) if it is restricted exclusively to the genitals, or (b) if it is connected with the overriding of disgust ... or (c) if, instead of being preparatory to the normal sexual aim, it supplants it" (p. 23).

This kind of aberration can be traced in Sergeant X in "For Esme with Love and Squalor," because many times he described the girl's and other children's appearances. In this sense, his behavior exceeds the normal looking existing in everyone. Even in his description he states the word scan for the way he looks at children:

Listening I scanned all the children's faces but watched one in particular, that of the child nearest to me, on the end seat in the first row. She was about thirteen with straight ash-blonde hair of earlobe length, an exquisite forehead, and blasé eyes that, I thought might very possibly have counted the house ... twice between the verses I saw her yawn. It was a ladylike yawn, a closed-mouth yawn, but you couldn't miss it (Salinger, 1961, p. 68).

In another part of the story, Sergeant X states how the girl chose a table in the teahouse that is good from his point of view, and also how they stared at each other: 
The choir member, taking off her coat as she walked across the floor, made the table selection - a good one from my point of view, as it was just eight feet or ten feet directly in front of me ... About the time their tea was brought, the choir member caught me staring over at her party. She stared back at me, with those house-counting eyes of hers, and then abruptly, gave me a small, qualified smile (Salinger, 1961, p. 69).

When she came and stood beside him, he looked at her dress as a careful inspection. And when he invited her to sit down and join him, he drew a chair for her and from his description of the girl's manner of sitting; it is obvious that he looked at her body carefully: "I got up and drew a chair for her, the one opposite me, and she sat down on the foreword quarter of it, keeping her spine easily and beautifully straight" (Salinger, 1961, p. 70).

Sergeant $X$ can be considered as an aberrant, because it seems that in that situation which there is no opportunity for sexual relationship, he preferred to look at his sexual object carefully and to scan her body thoroughly. In fact, looking supplanted the sexual aim. However, it is important to mention that his aberration cannot be put in the category of illness or abnormality.

\subsubsection{The After Effect of Infantile Object Choice}

According to Freud (1974), even after a person who has been fortunate enough to avoid an incestuous fixation of his libido, they do not entirely escape its influence. It often happens that a young man falls in love seriously for the first time with a mature woman or a girl with an elderly man in a position of authority. These figures are able to reanimate pictures of their mother or father. A man, especially looks for someone who can represent his picture of his mother.

The same is true about Esme. In "For Esme with Love and Squalor," Esme a thirteen-year-old girl somehow falls in love with a man, Sergeant X, who can represent her father. Because she suffers from lack of parents, she needs someone to reanimate the picture of them, especially that of her father's. In the course of the story in the teahouse, when Sergeant X tells her that he saw her at the choir practice, Esme answers that she saw the man too. It means that he was attracted by the girl at the same time in the choir practice. In another scene in the teahouse, when Esme's governess warns her not to bother the man, "she calmly moved her chair an inch or two so that her back broke all possible further communication with the home table" (Salinger, 1961, p. 71). That is to say, she wants to have a private table with the man without any interruption or disturbance. She repeatedly tries to convince the man that her hair is sloppy because of the rainfall:

She raised her hand to her wet head again, picked at a few limb filaments of blond hair, trying to cover her exposed ear rims.

"My hair is soaked wet," she said. "I look a fright." She looked over at me "I have quite wavy hair when it's dry."

"I can see that, I can see you have."

"Not actually curly, but quite wavy," she said. "Are you married?"

I said I was.

She nodded "Are you deeply in love with your wife? Or am I being too personal?" (Salinger, 1961, p. 71).

It is quite obvious that Esme is also choosing a sexual and love object. Even it is very important for her to know whether Sergeant $X$ is married or not, and if yes whether he is really in love with his wife or not. She tells the man that he has an extremely sensitive face, and she also asks him to say whether he found her terribly cold. In fact, she wants to know the young man's idea about herself. And when she wants to leave Sergeant X's table, she offers her apology again for her hair, and says that she has probably been hideous to look at. At the last scene in the teahouse less than a minute after Esme, Charles, and their governess leave the teahouse; she comes back into the tearoom and drags Charles to kiss the man, probably decorum does not allow her to do it herself. At the end she wishes the man return from the war with all his faculties intact. In fact, there is a pun about the word faculty. Literally, faculty means any of the powers of the body or mind. Therefore, she does not mean only to return from the war with his mental faculty intact but with all his 
faculties intact including his body faculties. Hence, it can be related to her sexual desire toward Sergeant X unless she could wish for the Sergeant X to come back from the war safely and alive, but she emphasizes to return with all his faculties intact.

In another part of the story, Esme tells the man that her father was killed in North Africa, and that Charles, her brother, misses their father very much. She states that Charles looks like her mother, and she looks like her father. She also adds that her mother was quite a passionate woman, an extrovert; on the contrary, her father was an introvert and needed more of an intelligent companion than the mother. As a matter of fact, Esme completely takes Sergeant X as her father and to some extent finds them alike, because she tells the man that she thought that he, Sergeant X, looked completely lonely, exactly like her father. Even their talents as a writer are similar. Besides, she describes her deceased father as if she describes her real love object: "He was an exceedingly lovable man. He was extremely handsome, too. Not that one's appearance matters greatly, but he was. He had terribly penetrating eyes, for a man who was intrinsically kind" (Salinger, 1961, p. 74). In fact, she was deeply in love with her father and now that her father is dead she looks for someone with the same characteristics. Hence, she transformed her love to Sergeant X. This affection to Sergeant $\mathrm{X}$ is so much that at the end of the story she sends her father's wristwatch along with a letter to the man. She is so interested that in the letter she states the exact date and time of their visit in that afternoon in the tearoom: April 30, 1944 between 3:45 to 4:15 P.M.

To sum up, it is really important to take note of the fact that some of Salinger's characters especially his heroes, are aberrant. Aberration is not considered as illness. In fact, it is finding another way to satisfy one's desires. So it would be irrational to put the blame on one who finds a substitute for something he cannot have at the moment or cannot accept as sexual object. Besides, it is necessary to remember that an individual may be aberrant in one sense, in looking, choosing children as sexual object or fetishism; therefore, a person may be aberrant in looking but not in fetishism. Additionally, Salinger's heroes' choosing a substitutes for their sexual desire is probably better than their antagonists who easily have sex immorally. Freud (1974) believes that anyone who is in any way, whether socially or ethically, mentally abnormal, they are invariably abnormal also in their sexual lives. It is important to remember that normality is not sanity and abnormality does not mean insanity. In fact, a socially abnormal person is the victim of the society itself and in Salinger's terms its phony members.

\subsection{Psychological Adjustment}

As briefly stated earlier, according to Freud (1974), it is generally difficult to be happy, and he enumerates three major sources of suffering: From one's own body, the outer world, and finally one's relations with other men. Relatively, he introduces the last one as more painful than any other. Freud (1972) claims that in order to alleviate our suffering and pains there should be some palliative remedies:

There are perhaps three of these means: powerful diversion of interest, which leads us to care little about our misery; substitutive gratification, which lessens it; and intoxicating substance, which makes us insensitive to it. Something of this kind is indispensable. Moreover, scientific works, works of art, fantasy, isolation and loneliness, and also love are among subdivisions of the main psychological adjustment (p. 28).

If human beings' physical and mental desires are not fulfilled, they would lose their composure and equilibrium. Therefore, in order to keep this balance in life, there should be a way to gratify these needs. To be more precise, life is a series of processes with which man's composure would be disturbed and then regained. These processes which begin with some requirements and end with great effort to gratify them are called adjustment. Adjustment consists of the psychological processes by means of which the individual manages or copes with various pressures. Because human needs cannot be met easily, man has to change the course of their activities to adjust themselves to the environment and gratify their desires. Sometimes, they have to find new ways of adjustment even for their survival (Shaffer \& Shoben, 1956). 
There are some mechanisms for adjustment of the individual. In fact dissatisfaction of the desires leads to failure and failure leads to anxiety. Therefore man's attempt for adjustment is nothing more than reaction against anxiety. Defense and escape mechanisms are two kinds of mechanisms that can be investigated in the behavior of Salinger's characters.

\subsubsection{Defense Mechanism}

As employed by Freud, the concept of defense mechanism referred to an unconscious psychological process. The person is said to be unaware of this process of self-deception. In Freudian theory, defense helped account for neurotic symptoms and irrational behaviors (Lazarus, 1969). These mechanisms do not alter the dangers and tensions themselves, but they change the view and understanding of the individual (Hilgard, Atkinson, \& Atkinson, 1975). Defense mechanisms are used only in necessary conditions and in facing difficult situations. Defense mechanisms consist of denial, repression, rationalization, reaction formation, projection, intellectualization, displacement, and compensation. In the study of Salinger's characters, four different kinds of defense mechanisms are noticeable: denial, rationalization, displacement, and most importantly compensation.

\subsubsection{Compensation}

Compensation is the excessive insistence on doing whatever alleviates anxiety. This mechanism takes the place of the original aim (Shaffer \& Shoben, 1956). Smoking and alcoholism are two examples among many examples of compensation.

In Salinger's stories, a lot of characters are heavy-smokers or alcoholics. Their behavior shows the application of compensation mechanism. Alfred Adler considered drinking as compensation for inferiority complex (Shamlu, 1989). In order to compensate the lost object, another one replaces it, as It can take the place of the former one. In other words, when someone wants to be liked, they may compensate their desires by excessive drinking and overeating (Hall, 1954). Like alcoholism, excess in smoking is a defense mechanism that is compensation. They smoke cigarettes, because they want to alleviate their anxiety. This behavior is sometimes applied by very healthy people just for removing everyday tension and anxiety.

In "For Esme - with Love and Squalor," after Sergeant X comes back from war he becomes a chain smoker as it is exactly mentioned in the story. It depicts crucially the application of compensation mechanism. He smokes, because he wants to alleviate the tension and problem war has created for him. It is important to remember that $\mathrm{X}$ becomes a chain-smoker after the war. It implies the fact that the more tension one has, the more one intends to smoke, drink alcohol, and use similar defenses. This is true about Lee in "Pretty Mouth and Green My Eyes" by displaying a mixture of guilt and compassion and excessive smoking.

\subsubsection{Children Isolation and Parental Alienation}

This kind of alienation and isolation has nothing to do with social pressure; but in this case children are the victims of harassment caused by relation to others and more specifically, parents. The most important factor which may create unhappiness for a child is family problems, especially on behalf of parents. Freud postulated that one of the primary wishes of early childhood is to be the center of attention and love from parents (Thurschwell, 2009), otherwise the child would feel a sense of loss in their life that leads to some harmful consequences.

According to Gardner (2002), parental alienation results from the parents. It refers to the wide variety of symptoms that may result from or be associated with a child's alienation from a parent. Children may become alienated from a parent because of physical abuse, with or without sexual abuse. Children's alienation may be the result of parental emotional abuse, which may be overt in the form of verbal abuse or more covert in the form of neglect. Children may become alienated as a result of parental abandonment. Ongoing parental acrimony, especially when associated with physical violence, may cause children to become alienated. Children may become alienated because of the behavior exhibited by a parent that would be alienating to most people, e.g., narcissism, alcoholism, and antisocial behavior. Impaired parenting can also bring about children's alienation. A child may be angry at the parent who initiated the divorce, believing that that parent is solely to 
blame for the separation. It is not uncommon for divorcing parents to be critical of one another in front of the children and even demean one another in front of the children. The children may believe these denunciations and become somewhat alienated from a parent.

Esme is also alienated and isolated: "Usually I'm not terribly gregarious." (Salinger, 1961, p. 72). Again loss of parents as well as people's hostility is the reasons for isolation and alienation of Esme and her little brother. Esme's father was an introvert as she says in the story; she also adds that she looks like her father. Psychologically, children whose parents use isolation as an escape mechanism tend to apply it more than other children. Therefore, Esme's isolation may be caused by that. Moreover, her comments about the Americans portrays her hatred toward them. "Well. Most of the Americans I've seen act like animals. They're forever punching one another about, and insulting everyone ..." (Salinger, 1961, p. 71). By this sentence, she introduces one group of phonies as the cause of unhappiness. So, isolation is one of the main mechanisms that characters in Salinger's stories would use to escape from intolerable and disgusting realities. Salinger himself emphasizes this mechanism in his works and depicts most of his characters isolated and alienated for different reasons.

In conclusion, Salinger's characters apply different mechanisms to gain happiness or to remove their tensions. It does not make any difference whether the character is a child, an adult, a woman or a man. Everyone uses these mechanisms as natural techniques and as suitable alleviating remedies. In fact, the study of mechanisms in the characters in Salinger's stories reveals that all human beings are common in using different mechanisms for their adjustment; but different people in different situations apply different mechanisms, so isolation, one of the main themes in Salinger's stories, sometimes is taken voluntarily as a kind of escape.

\subsection{Neurosis not Illness}

By analyzing Salinger's characters psychologically according to Freudian psychology of sexuality, psychological adjustments, and different kinds of mechanisms, one may also say that the characters could be divided into two main types: Normal and abnormal. Hence, the concepts of normality and abnormality should be studied closely in order to demystify Salinger's concepts of nice and phony and what he had in his mind.

Carefully studying Salinger's characters, one can say that a type of character is highlighted in his works. This character type, from which Salinger often choses his heroes, is most of the time alienated from the society and form the minority group of the society. Most of the time, they are called abnormal or antisocial. Moreover they are labeled as insane and ill. On the contrary, they are a very thoughtful, orderly, sensitive, and vulnerable part of the society. In his stories, Salinger tried to make readers feel sympathy toward this variety of characters, and as a member of this group he wanted to justify their behavior by introducing the opposite party, phonies, and highlighting their behavior in contrast to the first type. In order to study these two types of characters, first, it is useful to have the definition of the concepts of normality and abnormality. As the definition of the term neurotic and its different kinds may also be helpful to realize the difference between the two.

\subsubsection{Normal and Abnormal}

Who is normal, and who is called abnormal? Is abnormality the same as illness? Does the violation of normality lead to and justify inclusion in the category of mental ailments? According to Nazer (1988), psychologists have not yet been able to reach an agreement about the fact, because it is quite a dependent concept, but most of the modern psychologists are in opposition to traditional psychology. Today, those groups of people, who were formerly considered abnormal, are not thought as abnormal anymore. In other words, one is called abnormal who cannot adjust themselves to different situations; and in confronting different situations, show abnormal behaviors. This definition is not a proper one and it is not scientific. There are different definitions about abnormality. The most important ones refer to deviation from social norms and personal depression.

The first definition is deviation from social norms. There are special criteria or norms for acceptable behaviors in any society. Any behavior which clearly deviates from these criteria is called abnormality and the doer is called abnormal. That cannot be a proper definition, because 
some behaviors are considered normal in one society or a community, and abnormal in another. Besides, the concept of abnormality may differ during a period of time in a society. For instance, many years ago smoking marijuana or being naked on the beach were abnormal behaviors in America, but today these two kinds of behavior are considered as differences in life style, not abnormality. So the concepts of normality and abnormality are different in different societies and in different times. Therefore the definition of abnormality should be more than social compliance (Hilgard, Atkinson, \& Atkinson, 1975).

Individual depression is another important definition of abnormality. According to this definition one is called abnormal who suffers greatly from distress and anxiety. They are depressed, agitated, and anxious individuals. This depression can be the only criterion for being called abnormal in this definition. As stated in Hilgard, Atkinson, \& Atkinson (1975), none of these definitions are the satisfactory and true definition of abnormality, so it is better to define normality. Definition of normality is somehow more difficult than that of abnormality. Is normality the same as conformity? Traditional psychologists believed that normality is being able for an individual to conform to the environment. That is to say, one should conform to the rest of the society in order to have a suitable and happy life. This is a very ridiculous definition, because every good man who opposes the vicious community they live in, is not considered as normal. They are rejected, because they do not conform to the fraud community. In Salinger's stories, the heroes are those who cannot conform to the false society and so they are labeled as abnormal or even insane. Today a host of psychologists believe that unwilling conformity to the ideas of majority would have such a negative effect that there cannot be a definite and true interpretation of the normal and ideal personality ( $\mathrm{p}$. 188).

In conclusion, in every community there is a group of the minority who are considered as abnormal - people who are neither insane nor terrible. Their only fault is their nonconformity to their community and for this reason they are labeled as abnormal. In addition, as mentioned formerly, there are not any explicit definition of the terms normality and abnormality, so the question raised here is in which category this abnormal group of people falls. Are they called Neurotics?

\subsubsection{Neurosis}

According to Nazer (1988), for a long time neurotics were considered as psychotics. It was believed that they could not feel what it means to like others or to be liked, so they could not like anyone (p. 40). A neurotic in that time was the one who was labeled not only as abnormal but also as a severely ill person. Fortunately, that is proved to be just a misconception and views toward neurotics have become optimistic. A psychoneurotic feels lack of affection from others toward them. They are always anxious, unhappy, and dissatisfied with themselves and others; therefore, they try to handle the situation and overcome their anxiety through some mechanisms. Of course, these people are completely organized and orderly.

According to Shamlu (1989), neurotics excessively use mechanisms for adjustment. They use mechanisms like denial, repression, reaction formation, and isolation. Poor sexual potency among the neurotics appears in different compensating forms like avoiding the opposite sex, putting blame on the spouse, indulging in immoral sexual relationship, and even experiencing sexual aberration. Neurotics try not to show their anger directly. Most of the time, they will show their rage by pertinacity and negativism. They have ambivalent feelings toward others, because on one hand they are aggressive toward their environment and society and on the other their need for others' affection make them avoid aggression. They desperately like to be liked by others. They try to find one or some stronger friends than themselves to pass the buck to them, namely, they want their friend(s) to carry the burden of their heavy psychic load. This friend can be another psychoneurotic, a matched friend or a child, and it is exactly what is seen in Salinger's stories (Sybil and Esme).

Because identifying psychoneurosis is very difficult and also essential, psychologists tried to classify neurosis into some kinds. But, generally psychologists have not been able to offer a proper classification for psychic ailments yet. Also they unanimously believe that this classification will not help to identify the essences and treatments of these psychic illnesses (Shamlu, 1989). 


\subsubsection{Causative Factors of Neurosis}

It is not clear what the causes for neurosis disorders are but psychologists have focused on psychic and socio-cultural factors.

\subsection{Psychic Factors}

The most important factor in creating neurosis is the psychic factor. The psychic symptoms of neurosis are repressed angers, feeling of inferiority, anxiety, fear, and excessive use of defense mechanisms. All these form in childhood. It is remarkable that parents of neurotic children have some problems which affect the relationship not only between themselves as husband and wife but also the relationship between them and their children. These parents make the children alienated and outcast and also make them avoid expressing their emotions (Shamlu, 1989). Different researches have shown that there is ill relationship between neurotic children and their parents. In fact, such parents are not alike and unified in their children's training. The mother may be aggressive, but in contrast the father may be isolated and pathetic. According to researches, the role of father is more important in forming the personality of the child. Identification is another important factor in neurosis. As a matter of fact parents inject and amplify their behaviors in their children. It is also true of neurotic parents. Neurotic children are discontent of their parents, but unconsciously they imitate their parents' behaviors (p. 140).

\subsection{Socio-Cultural Factors}

Another important factor which makes a child neurotic is loss of one of the parents. According to recent researches, loss of the father is one of the crucial factors in children neurosis: loss of mother or both in schizophrenic people (Shamlu, 1989). Loss of love or emotional support is a precipitating factor for creating neurosis, especially depression neurotics, even in adults. To lose love, or even to be threatened with its loss, is for them to experience an attack upon the most vulnerable part of their personality system. Loss may mean both the death of a loved one or loss without death. For example, being deserted or getting divorced are considered as the latter forms of loss. A leader may lose their followers. A loved one may go away emotionally without leaving physically. These losses disturb a person's internal equilibrium and arouse in them dejection and hostility (Shamlu, 1989).

\subsubsection{War Neurosis}

Neurosis of war is a kind of traumatic neurosis which comes from different events in war. A person may turn back from war physically healthy but mentally ill. There are a lot of causes that lead to war neurosis. For example, fear of death, sleeplessness, frustration, homesickness, and feeling of guilt from killing the enemy or terrible incidents which leave a friend or a partner dead or injured. Symptoms of war neurosis to name just a few are depression, insomnia, discipline, and alienation (Shamlu, 1989). War is the concept that is blamed by Salinger because of its sociological, economical, physical, mental, and other terrible consequences. The setting and the mood of most of his stories signify war and after-war period. War neurosis is one of the disorders that Salinger indirectly illustrated in his stories.

In Nine Stories, the best example of a war neurotic is Sergeant $\mathrm{X}$ who at last turns to a psychotic. Sergeant X is one of Salinger's characters who is a war neurotic. At the beginning of the story, he seems a mild neurotic. Isolation is palpable in him and the rest of the soldiers in the group. In the pre-invasion training course among the sixty soldiers in the group, lack of communication is evident. As Sergeant X mentions: "There wasn't one good mixer in the bunch and when we spoke to each other out of the line of duty, it was usually to ask somebody if he had any ink he wasn't using" (Salinger, 1961, p. 66). It is an evidence for the fact that all of the soldiers are isolated, because nobody talks to nobody in the group. It is definitely due to the war time and perhaps their training course. For three years, sergeant X has been in the Army, so his three-week training course is not his first experience about war. As stated before, homesickness, sleeplessness, and frustration may be the causes of neurosis in the Army and the special pre-invasion training course like what X took part in; there are a lot of hard situations which may cause neurosis. It was said that one of the 
conspicuous symptoms of neurosis is being orderly. Therefore referring to the story, $\mathrm{X}$ is an orderly man. He says:

I came away from the window and put on my rain coat, cashmere muffler, galoshes, woolen gloves, and overseas cap (the last of which, I'm still told, I wore at an angle all my own slightly down over both ears).Then, after synchronizing my wrist watch and the clock in the latrine, I walked down the long, wet cobblestone hill into town (Salinger, 1961, p. 67).

Another symptom which shows Sergeant $X$ as a psychoneurotic is his sexual aberration discussed before. It can be inferred that he likes to be liked by others and as mentioned before it is one of the features of neurotics that they excessively desire to be liked by others and to be the center of attention. Almost at the last part of the story Sergeant X opens for the third time the book he got from a girl who was arrested by him. It is written in red ink, in a small hopelessly sincere handwriting "Dear God, life is hell" (Salinger, 1961, p. 79). Firstly, it shows the girl's depression or isolation, because this kind of handwriting, small and hopeless, signifies that the writer of the words is low-spirited. Sergeant X reads it three times likely because he feels affinity with the German girl. Then, he writes down under the handwriting: 'Fathers and teachers, I ponder 'What is hell?' I maintain that it is the suffering of being unable to love" (Salinger, 1961, p. 79). So he greatly feels lack of affection, and he excessively likes to be liked. Consequently, he shows his aberration, and he uses love as another kind of mechanism as stated in Freud (1972).

Also, Sergeant X adopts 'compensation' as a defense mechanism. He smokes cigarette after he comes back from the war. He becomes a chain smoker. That is to say he uses defense mechanisms excessively; exactly what psychoneurotics do. Of course, after the war in the second part of the story he becomes a psychotic, and he never comes from the war intact. His mental breakdown is completely obvious through the course of the second part of the story. It seems that after the war, his neurosis is so severe that he becomes a psychotic. Psychosis is extreme mental disorganization which is considered as illness, and the patient may need to be hospitalized (Bullock, Trombley, \& Lawrie, 1999).

In the second part of the story, the reader is informed that Sergeant $\mathrm{X}$ has recently left the hospital, and it can be the harsh form of neurosis. Exactly after the war he becomes a chain-smoker, his fingers bump gently and incessantly against one another; abruptly and with no warning he thinks that he felt his mind dislodge itself and teeter like insecure baggage on an overhead rack, and he also gets the shakes. He presses his hands against his temple. To describe his illness, Salinger wrote: "He ached from head to foot, all zones of pain seemingly interdependent. He was rather like a Christmas tree whose lights, wired in series, must all go out if even one bulb is defective" (Salinger, 1961, p. 79). Even Sergeant X indirectly declares his illness. His comments about Loretta, Clay's girlfriend, a student in psychology, shows that his nervous breakdown is duo to the war.

"Clay stared at him for a moment, then he said ...' I wrote Loretta you had a nervous breakdown.'

"Oh?"

"Yeah. ... she is majoring in psychology... You know what she said? She says nobody gets a nervous breakdown just from the war and all. She says you probably were unstable like, your whole goddam life"

$\mathrm{X}$ bridged his hands over his eyes ... and said that Loretta's insight into things was always a joy" (Salinger, 1961, p. 81-2).

Sergeant X knows that his nervous breakdown is because of the war. Also, in another part of the story Clay reminds $X$ of the moment he shot the cat in the war. Clay said that according to Loretta and the whole psychology class and even her professor, he (Clay) was temporarily insane from the shelling (Salinger, 1961, pp. 81-2). 
Then, $\mathrm{X}$ tried to use 'rationalization' as a mechanism so excessively that it made Clay angry. Sergeant X says:

You weren't insane. You were simply doing your duty. You killed that pussycat in as manly a way as anybody could've under the circumstances. That cat was a spy. You had to take a pot shot at it. It was a very German midget dressed up in a cheap fur coat. So there was absolutely nothing brutal, cruel, or dirty, or even ... (Salinger, 1961, pp. 81-2).

Loretta by this commentary contradicts her idea that war never causes nervous breakdown. Salinger wants to show his pessimistic view about psychologists and also the misconceptions about different psychological terms. It can be inferred that Loretta and her whole classmates and even her professor misuse the term insane. But above all, it is highly obvious that Sergeant X as mentioned in the story does not come from the war intact, namely, his mild neurosis turns to psychosis after the war.

\subsubsection{Depression Neurosis}

According to Cameron (1963), normal depression in human beings is a reaction to an extrinsic factor which the person is aware of. In neurotic depression, the extrinsic factor may be loss of someone or failure in life or job, etc. The basic symptoms are self-deprecation, dejection and appeals for reassurance, and feeling of hopelessness and worthlessness. The neurotically depressed person no longer finds interest in people, things or activities. He looks to other people for emotional support. They do not demand conformity or obedience; they do not try to direct what others shall do.

Children in Salinger's stories are center of attention. Most of the children in his stories are neurotic children. They are not like ordinary children in every society. They are not that much childlike. They speak as if they are knowledgeable adults. They cannot communicate with their parents and every adult. They find their friends if possible among the special kind of adults; those who lack the dreadful characteristics of other adults or even their parents. The causes of neurosis in children are for the great part psychic factors. As demonstrated in the psychic factors for neurosis, parents and family relationship play an indispensable role in making a child and consequently an adult neurotic. Mismatched parents and those who have some problems and a lot of arguments, make their children neurotic, alienated, and depressed. To study some of the neurotic children, Salinger's stories have a lot of good examples.

From the very beginning in Nine Stories, Sybil reflects herself as a neurotic child. The ill relationship between Sybil and her mother probably is due to the poor relationship between her parents. As mentioned before lack of one of parents can be a spark for neurosis in children. The absence of father in the story represents the probable problem between Sybil's parents. Her mother is so indifferent to her that she firstly lets her go to the beach alone and secondly makes her wear a two-piece swimsuit, "one piece of which she would not actually be needing for another nine or ten years" (Salinger, 1961, p. 12). Of course "A Perfect Day for Bananafish" is such a short story that the little girl has not been characterized fully, as her mother's short presence in the story and her father's complete absence do not give enough information about her family, so what the reader has in his hand about Sybil is that she suffers from ill family relationship, and she is an isolated little girl.

"For Esme with Love and Squalor" is the famous short story that holds an amazing example of a neurotic child. Esme's special features as a psychoneurotic are her isolation, her hostility toward American people, and her need for emotional support from someone lovely and trustful. It is important to state that the causes of the neurosis in Esme are both psychic and socio-cultural factors. Loss of the parents is the most important factor in her neurosis. In Esme's case, it seems that the death of her father is a great loss for her. On the other hand, it can be suggested that she might had identified with her father, and that can be another reason for neurosis among children. In the story Esme introduces his father as an introvert and her mother as an extrovert. She also adds that she looks like her father. Although it is impossible to be highly sure, considering Esme's father as a psychoneurotic cannot be a wrong guess. Another factor which may cause neurosis is the socio- 
cultural factor, that is, an external factor with the society, its people, and events like war. Because the setting of the story is in war time, the war itself can be another reason which causes some disorders not only in Esme but also in every person in the society (here Sergeant X). Probably phony people in the society, violent Americans, can be another reason making people and children like Esme psychoneurotic.

According Shamlu (1989), loss of father is an important factor making a child neurotic. According to Soleimani Fakher (2004), the age of children is important when they lose their fathers. Children under seven years old who have lost their fathers show more limitation in their social communication. Also they are more isolated than children who enjoy their father's presence. There are a lot of suitable examples in Salinger's stories. Most of the children especially the neurotic ones suffer from loss of either both parents or at least one parent. It is noticeable that the loss of father, whether physically or emotionally, is more frequent in the stories. Of course, it should be mentioned that physical separation from the father is not the most significant factor for psychological disorders, but more important is ill family relationships. In other words children who are in an unsuitable family relationship are more exposed to psychological disorders, as that is what can be seen in Sybil, Romana, Lionel, and Teddy.

As mentioned before, two types of characters are distinguishable in Salinger's stories, but they could not be classified as normal and abnormal, because there is no definite definition of these terms. Therefore, it is better to call the second group neurotic and the second group non-neurotic. The second type is not called healthy and normal, because the first type is not ill or abnormal. It is noticeable that Salinger did not choose his characters and even heroes only from neurotics, rather he sometimes adopts the second type as his heroes to show the oppositions between the two. That is to say, he wanted to arouse his readers' sympathy toward the neurotics and prove that they are not ill, but that they are prone to illness in the case of more pressure and more anxiety. On the other hand, by introducing the second group as phony, he tried to justify the hostility of his heroes toward those people that form the majority of the society. He shows the majority of the society as people with the same disorders but in different ways, because when any immorality and vice becomes rampant in a society, it turns to a custom, and its terrible effects are overlooked. Hence, Salinger tries to magnify these conformist characters, those who consider themselves and their behavior normal, and condemn and disdain the minority group or the neurotics as abnormal, ill, and insane. By comparing these two types of characters, it will be clear that they have some traits in common.

Generally, psychiatrists believe that everybody is a psychoneurotic. Some others believe that neurosis and psychosis are basically different. Psychoneurotic people suffer from emotional disorders, whereas psychotic people unlike the former ones suffer from hallucination, paranoia, and other sever illnesses which ultimately end in hospitalization. Also, psychiatrics believe that both psychoneurosis and psychosis result from the same origins and factors. A psychoneurotic will turn to a psychotic if he suffers from more incessant pressures (Sergeant X). It is important to remember that Salinger's characters are not antisocial, because antisocial people are those who act in opposition to the common people of the society. They tell lies, they do not like other people, and they ignore other's rights. Also, they make a lot of troubles for the society. Carefully studying characters in Salinger will show that they are not antisocial. They like to have an ideal, innocent, and moral society. Instead of bothering others, they prefer to live in their solitary and loneliness. Furthermore, what can be learned from Salinger's stories is the fact that the minorities in every sense are considered as abnormal merely because they differ from the rest of the society (majority). Morris (1969) explains the difference between minorities and majorities with a very remarkable example. Morris believes that if some people, for example, with some body defects are blamed because of the defects they are not responsible for, they will show aggression in their behavior. Unfortunately, they call this group of minorities as 'the others'. The following imaginary example can clarify the subject better:

Look at that green-hair man beating a child.

That green-hair man is bad.

Green-hair people are bad. 
Green-hair people attack everyone.

There is another green-hair man! Beat him before he beats you.

(Green-hair man, who has not done anything wrong to make anybody angry, has to defend himself and beats the attacker).

You see! It means: green hair people are bad.

Beat every green-hair man (p. 164).

It can be concluded that if the green-hair man who was beating a child did not have any special sign (green hair) to be recognized as 'other', he would have been considered as normal and his behavior would have been considered as normal, too. So, neurotic people and those who think differently from the rest of the society should not be considered as abnormal and ill, because in their own community and among those who are exactly like them, they are considered as normal. Consequently, if the number of these people (others) increases and becomes greater than the former (majority), they will be considered as normal and the other party as abnormal. As a matter of fact, Salinger's characters may be called 'others' because they are fewer in number than 'non-others'.

\section{CONCLUSION}

In this study, the misconception that the psychoneurotic are severely, mentally ill would be rejected. In fact, the researchers try to convey Salinger's view that such people have different attitudes and way of thinking in comparison to the rest of people in a society, and consequently such minority groups are labeled as abnormal. Hence, the first group who consider themselves as normal adopt similar or different kind of mechanisms in response to their anxiety just as the second group does. In fact, according to recent researches in psychology, the second group or psychoneurotic are not considered insane. They are quite talented, they are able people, they are qualified, but they cannot get in touch with people who live in the world that Salinger calls phony. Most of them adopt isolation as a kind of escape mechanism as studied closely in this study.

Psychological study of Salinger's characters reveals some important points. Salinger's favorite themes, including the alienation of the individual and the terrible effect of war are studied in this study. As a whole, two important results are taken from this study. The first one is about Salinger's literary works (here some of his short stories), and the second one may well point to Salinger himself as a writer with a private life. Salinger in his stories gave the leading role to characters who are somehow different from the other characters in the stories. In some of his stories, an adult character is the protagonist of the story and in some others, a child. Sometimes, both of them are present in the stories and make interesting and special friendship and companionship with each other. Indeed, Salinger divided his characters into two main groups. The first group, whose members are Salinger's heroes, are adults with special characteristics which distinguish them from the second group. Moreover children are included in the first group and to some extent in opposition to the second group. Of course, it is important to remember that children in Salinger's stories are not ordinary children we know in reality. Most of them have the same characteristics that the adult heroes do. After studying Salinger's heroes it is revealed that most of these special kinds of adults and some of the children are neurotic people. They are depressive, alienated, and isolated, and they seek true love in their lives. Whenever they find love and compassion, especially on behalf of someone in their own group, they try to communicate with them, but unfortunately their distress is so severe that they cannot be saved by the temporary love object, for love and other psychological mechanisms can soothe the anxiety temporarily. Thus, sometimes the characters' anxieties lead to their destruction.

Salinger tried to arouse the feeling of sympathy toward his heroes. Referring to his stories, it can be inferred that he did not want to say solely that all adults are immoral, bad, and according to himself, phony. He believed that the first group consists of special number of adults and children who are somehow different from the rest of the phony people in society. Although some of them are neurotic and have some psychic disorders, they are talented, reasonable, kind, and in Salinger's 
view innocent. Moreover, in most cases, they are not responsible for their own defects or disorders; therefore, they should not be blamed for the disorders resulting from war, social pressure, and poor family relationships. In addition, they do not disturb anyone in their community and like to live in their own solitary life emptied from people. Above all, this study not only clarifies Salinger's heroes' behaviors, but also shows that the other group or commonality also has some of the same characteristics, but in other ways. In fact what differentiate between these two groups of characters are vulnerability and sensitivity of the first group (Salinger's heroes).

As mentioned before, some members of the first group are neurotic or show some characteristics of neurotic people. They should not be called ill, because in modern psychology neurotic people are not considered as ill anymore. They are people with different attitudes from what is considered as normal in a society. Looking more closely into the stories, the heroes are depicted as innocent. By innocence it means that their sexual tendencies do not end in intercourse, and as a whole they do not intend to disturb other people. Salinger exaggerates slightly about the innocence of his characters. In reality, neurotic people have severe form of sexual aberration and it ends in intercourse. That does not mean that Salinger intentionally tries to show his heroes as neurotic. According to psychological character study, his heroes are recognized as neurotics, and it can be concluded that his characters can represents both the people of the society in his own time as well as he himself. Certainly, he reflected the chaotic situation in war period through his distressed characters. On the other hand, his characters can represent Salinger himself that is the second important result of the study. A simple comparison between Salinger and his characters shows that he created his characters from his own dispositions and situation. In many of his stories, characters are military soldiers or personnel. As indicated in Grunwald (1962), in France, Staff Sergeant Salinger had an audience with war Correspondent Ernest Hemingway, who read Salinger's work, and possibly in appreciation of it ("Jesus, he has a helluva talent"), took out his Luger and shot the head off a chicken, Salinger used a similar incident in "For Esme with Love and Squalor" (p. 14). It is mentioned in the introduction of the study that both Salinger and his creation, Holden, attended prep schools and were members of the fencing team. During the prep-school of both Salinger and Holden, a suicide and a nervous breakdown of a fellow student occur. Moreover according to Grunwald, In Florida, Salinger once did befriend a girl much younger than him (Sybil), and went on seeing her until she was in college (p. 20). Looking more carefully shows the similarity between the families in the stories (especially the Glass family) and Salinger's own family. Moreover, he seems to have a meager knowledge about psychology, because in his stories he used a lot of psychological terms. Of course it should be mentioned that his wife was a psychiatrist. Hence, his works by some means are taken from his own life. In fact, according to Freud, by interpretation of the writer's work which can be considered as his dream, his unconscious will be revealed. Salinger is a beautifully deft, professional performer who gives us a chance to catch quick, half-amused, half-frightened glimpses of ourselves, and our contemporaries, as he confronts us with his brilliant mirror images (Salami, 1999).

\section{References}

[1] Alexander, C. (1996). J. D. Salinger's Franny and Zooey and, nine stories: a critical commentary. New York: Monarch Press.

[2] Bullock, A., Trombley, S., \& Lawrie, A. (1999). The new Fontana dictionary of modern thought. London: HarperCollins Publishers.

[3] Cameron, N. (1963). Personality development and psychopathology: a dynamic approach. Boston: Mifflin Company.

[4] Freud, S. (1938). The basic writings of Sigmund Freud (A. A. Brill, Trans.). New York: The Modern Library.

[5] Freud, S. (1968). Beyond pleasure principle (J. Rickman, Trans.). London: The Hogarth Press. 
[6] Freud, S. (1972). Civilization and its discontent (J. Riviere, Trans.). London: The Hogarth Press.

[7] Freud, S. (1974). Three essays on the theory of sexuality (J. Strachey Trans.). London: The Hogarth Press.

[8] Gardner, R. A. (2002). "Parental alienation syndrome vs. parental alienation: which diagnosis should evaluators use in child-custody disputes?" The American Journal of Family Therapy, 30(2), 93-115. http://www.fact.on.ca/Info/pas/gard02b.htm

[9] Grunwald, H. A. (Ed.). (1962). Salinger: a critical and personal portrait. New York: Harper.

[10] Gwynn, F. L, \& Blonter J. L. (1962). The fiction of J. D. Salinger. University of Pittsburg Press.

[11] Habibi Nesami, M., Montashery, I., Shahbazi Moghadam, M. (2011). Glass characters in J. D. Salinger's "a perfect day for Bananafish": a psychoanalytical study. International Journal of Social Sciences and Humanities Review, 2(4), 135-140.

[12] Hall, C. S. (1954). A primer of Freudian psychology (1 ${ }^{\text {st }}$ ed.). Cleveland: World Pub. Co.

[13] Hilgard E. R., Atkinson R. L., \& Atkinson R.C. (1975). Introduction to psychology. New York: Harcourt Brace Jovanovich.

[14] Lazarus, R. S. (1969). Patterns of adjustment and human effectiveness. New York: McGrawHill.

[15] Morris, D. (1969). The human zoo. New York: Kodansha America, Inc.

[16] Nazer, M. (1988). The psychology of the abnormal and psychotic. Tehran: Shargh-e Tehran Publications. [Persian]

[17] Quinodoz, J. M. (2004). Reading Freud: a chronological exploration of Freud's writings (D. Alcorn, Trans.). London/New York: Routledge.

[18] Sachs, H. L. (1975). Dynamic personal adjustment: an introduction. New York: Behavioral Publications, Inc.

[19] Salami, I. (1999). Thirty great novels. Tehran: Mehrandish Books.

[20] Salinger, J. D. (1951). The Catcher in the Rye. Great Britain: Penguin Books.

[21] Salinger, J. D. (1961). Nine stories. New York: The New American Library.

[22] Shamlu, S. (1989). Textbook of psychopathology. Tehran: Roshd Publications.

[23] Shoben, L. F., \& Shaffer, E. J. (1956). The psychology of adjustment. Boston: Houghton Mifflin Co.

[24] Soleimani Fakher, O. (2004, September 15). Life without a father. Hamshahri Newspaper.

[25] Thurschwell, P. (2009). Sigmund Freud. London: Routledge. 